\title{
USP39 promotes colorectal cancer growth and metastasis through the Wnt/ $\beta$-catenin pathway
}

\author{
XIANWEN YUAN ${ }^{1,2^{*}}$, XITAI SUN ${ }^{1,2^{*}}$, XIAOLEI SHI ${ }^{1,2}$, HAO WANG $^{2}$, GUOYI WU $^{1,2}$, \\ CHUNPING JIANG ${ }^{1,2}$, DECAI YU ${ }^{1,2}$, WEIWEI ZHANG ${ }^{1,2}$, BIN XUE $^{3,4}$ and YITAO DING ${ }^{1,2}$
}

\footnotetext{
${ }^{1}$ Department of Hepatobiliary Surgery, The Affiliated Drum Tower Hospital of Nanjing University Medical School, Nanjing, Jiangsu 210008; ${ }^{2}$ Jiangsu Province Key Medical Center for Hepatobiliary Disease, Nanjing, Jiangsu 210008;

${ }^{3}$ Jiangsu Key Laboratory of Molecular Medicine, Medical School of Nanjing University, Nanjing, Jiangsu 210093;

${ }^{4}$ MOE Key Laboratory of Model Animals for Disease Study, Model Animal Research Centre and the School of Medicine, Nanjing University, National Resource Centre for Mutant Mice, Nanjing, Jiangsu 210093, P.R. China
}

Received September 4, 2016; Accepted January 31, 2017

DOI: $10.3892 / o r .2017 .5454$

\begin{abstract}
In the present study, we first examined the expression of USP39 protein using tissue array containing 90 colorectal cancer (CRC) tissues and 9 clinical samples, and observed that it has significantly higher expression in cancer tissues as compared to the corresponding adjacent normal tissues. Also, we tested USP39 expression level in four CRC cancer cell lines and identified that it indeed had higher expression in all these CRC cell lines. In addition, its knockdown inhibited not only the cell growth of SW480 and HT29 cells, but also the cell migration and invasion. Further analysis of its molecular mechanism suggested that the expression of four crucial proteins of $\mathrm{Wnt} / \beta$-catenin pathway, including $\beta$-catenin, TCF4, MMP2 and MMP9 was reduced as a result of USP39 knockdown. Taken together, all these findings demonstrated that USP39 protein plays an important role in the growth and metastasis of colorectal cancer mainly through Wnt/ $\beta$-catenin pathway.
\end{abstract}

\section{Introduction}

Colorectal cancer (CRC) is one of the most prevalent tumors associated with cancer-related death worldwide (1). The

Correspondence to: Professor Bin Xue, Jiangsu Key Laboratory of Molecular Medicine, Medical School of Nanjing University, Nanjing, Jiangsu 210093, P.R. China

E-mail: xuebin@nju.edu.cn

Professor Yitao Ding, Department of Hepatobiliary Surgery, The Affiliated Drum Tower Hospital of Nanjing University Medical School, No. 321 Zhongshan Road, Nanjing, Jiangsu 210008, P.R. China E-mail: dytnanjing1983@126.com

${ }^{*}$ Contributed equally

Key words: USP39, colorectal cancer, metastasis development of drug resistance and relapse with refractory disease, further limits the 5-year survival of metastatic CRC patients to less than $10 \%$ (2). Aberrant alternate splicing commonly observed in cancer cells, has been implicated in the transformation of many types of cancers $(3,4)$. For instance, many genes involved in the proliferation and invasiveness of cancer cells, are frequently alternatively spliced. These specific splice variants, which are often upregulated in many tumors, stimulate cell proliferation and migration and thus, contribute to the transformed phenotype (5). However, the roles of different spliced variants along with their splicing factors, involved in controlling the alternate splicing have not been completely appreciated in tumor development.

USP39 is one of the deubiquitinating enzymes (DUBs) which do not have ubiquitin protease activity due to lack of three important residues important for the protease activity (6). It encodes a conserved protein, U4/U6 U5 tri-snRNP, which has $65 \%$ overall homology with yeast Sadlp splice factor, and has been implicated in the assembly of mature spliceosomes. In vitro studies have indicated that Usp39 is essential for pre-mRNA splicing, but not for the stability of the spliceosome complex after its formation (7). USP39 has also been shown to be essential in the spindle assembly checkpoint and controls the Aurora B mRNA levels in U2OS cells (6). In addition, USP39 mutation in zebrafish induce G1/S arrest by rb1 splicing defect, and the e2f4 appears to be also the target of USP39. This mutation eventually contributes to adenohypophyseal sensitivity to $\mathrm{rb} 1$ and e2f4, and lead to pituitary tumorigenesis (8). Similarly, USP39 mutation in breast cancer cells, also implicate it as an oncogenic factor, and its downregulation induced apoptosis of the MCF-7 breast tumor cells (9). A study (10) has further demonstrated that USP39 overexpression enhanced the proliferation of prostate cancer cells, thereby suggesting that USP39 may also play a key role in prostate cancer development. All these studies have emphasized that USP39 may be a potential molecular target of cancer.

In the present investigation, we first explored the relationship between USP39 expression and colorectal cancer. Initial 
results suggested that USP39 expression levels were higher in tumor tissues than in adjacent normal tissues, and thus, indicated that USP39 may act as a new target in colorectal cancer. To further verify our hypothesis, we tested USP39 expression in four different colorectal cancer cells, and later by knocking down its expression by RNA interference (RNAi) technology in SW480 and HT29 colorectal cancer cell lines, we investigated its role in in vitro cell invasion and migration. Our results indicated that USP39 inhibition suppressed the migration of colorectal cancer cells through regulation of $\mathrm{Wnt} / \beta$-catenin pathway.

\section{Materials and methods}

Cell culture. Human CRC cell lines, LoVo, Caco2, SW480 and HT29 were purchased from the Shanghai Institutes for Biological Sciences (Shanghai, China). LoVo cells were cultured in $\mathrm{F}-12 \mathrm{~K}$ medium, and $\mathrm{Caco} 2$ cells in minimum essential nedium (MEM), SW480 were cultured in L15 medium and HT29 cells in McCoy's 5A medium. The culture mediums of three cell lines were supplemented with $10 \%$ fetal bovine serum (FBS), $100 \mathrm{U} / \mathrm{ml}$ of penicillin and $100 \mu \mathrm{g} / \mathrm{ml}$ of streptomycin. The Caco2 cells, instead were cultured in medium with $20 \% \mathrm{FBS}$, in addition to other ingredients. All cell types were incubated at $37^{\circ} \mathrm{C}$ with $5 \% \mathrm{CO}_{2}$.

Immunostaining of tissue microarray and clinical samples for USP39 expression. Colorectal cancer tissue arrays were purchased from the National Engineering Center for Biochips (Shanghai, China). In addition, the surgically excised CRC tissues and surrounding non-tumor colon tissues were obtained from $9 \mathrm{CRC}$ patients at the Affiliated Drum Tower Hospital of Nanjing University Medical School. This study was approved by the Ethics Committee of the Affiliated Drum Tower Hospital of Nanjing University Medical School and patient informed consent was obtained. The USP39 expression in these tissues was evaluated by immunohistochemical staining with USP39-specific antibody (1:500 dilution; Abcam, Cambridge, UK). The expression was scored according to the staining intensity and the percentage of cells stained. The final staining scores were calculated by multiplying staining intensity with percentage of stained cells.

MTT assay. Human CRC cells $\left(1 \times 10^{5}\right.$ in $\left.0.2 \mathrm{ml} / \mathrm{well}\right)$ in three replicates, were seeded in 96-well plate in the complete medium and cultured at $37^{\circ} \mathrm{C}$ for $1-5$ days. The $100 \mu 1(5 \mathrm{mg} / \mathrm{ml})$ of MTT solution was added into each well and incubated at $37^{\circ} \mathrm{C}$ for $4 \mathrm{~h}$. Next, the supernatant was removed and $150 \mu \mathrm{l}$ of dimethyl sulfoxide (DMSO) was added per well. The plate was oscillated for $30 \mathrm{~min}$ at room temperature, and later the absorbance at $490 \mathrm{~nm}$ was measured. The values were calculated after background subtraction. All the MTT experiments were repeated at least three times.

USP39 knockdown. The lenti-shRNA vector system to knock down USP39 was constructed, packed and purified by Shanghai GeneChem, Co., Ltd., (Shanghai, China) and was later manipulated according to the protocol provided by the manufacturer.
Wound healing assay. CRC cells seeded in 6-well plates at a density of $10^{5}$ cells/well, were incubated for $48 \mathrm{~h}$. A $2-\mu 1$ pipette tip was used to scratch a linear wound in the cell monolayer and cells were then allowed to grow in complete media. Images were taken at 0 and $48 \mathrm{~h}$ after wounding, respectively.

Transwell migration. Cell migration assay was performed using Boyden chambers (Transwell Costar; 6.5-mm diameter, $8-\mu \mathrm{m}$ pore size) according to the manufacturer's instructions. Briefly, $3 \times 10^{4}$ cells were resuspended in $500 \mu 1$ of serum-free medium and seeded in the upper chamber. In parallel, $800 \mu 1$ of the complete medium containing $10 \%$ FBS was added into the lower chamber. Cells were allowed to migrate for $48 \mathrm{~h}$. Later, migrated cells were stained with $1 \%$ crystal violet and the cell numbers were counted under a microscope. Six fields of view from each chamber were randomly selected for cell counting.

Quantitative real-time PCR. Total RNA was extracted from CRC cell lines using TRIzol (Invitrogen) following the manufacturer's instructions. qRT-PCR was performed as previously descibed (11). Briefly, $1 \mu \mathrm{g}$ of total RNA was transcribed using random primers and PrimeScript reverse transcriptase (Takara Bio, Dalian, China). Quantitative PCR reaction for USP39 and GAPDH genes was carried out using SYBR-Green qPCR kit (Takara) on a fluorescent temperature cycler (Mx3000P realtime PCR system; Stratagene, La Jolla, CA, USA). The following primers were used to detect the expression of USP39 (F, 5'-CCAGCGATGGCAACTAC-3' and R, 5'-ACCACAA CGGAAACACG-3') and GAPDH (F, 5'-TGACTTCAACAG CGACACCCA-3' and R, 5'-CACCCTGTTGCTGTAGCCA AA-3'). The PCR reaction was performed with the following parameters; denaturation at $95^{\circ} \mathrm{C}$ for $5 \mathrm{~min}$, followed by 45 cycles of $95^{\circ} \mathrm{C}$ for $15 \mathrm{sec}$ and $60^{\circ} \mathrm{C}$ for $1 \mathrm{~min}$. Finally, using GAPDH as an endogenous control, relative gene expression of USP39 was determined by comparative $\Delta \mathrm{Ct}$ method using the Stratagene analysis software. The experiment was repeated at least three times.

Western blot analysis. CRC cells were lysed in RIPA lysis buffer (Tiangen Biotech, Co., Ltd., Beijing, China) and extracted proteins $(20 \mu \mathrm{g})$ were separated on a $10 \%$ SDS-PAGE gel and then transferred to Immobilon-P polyvinylidene difluoride membrane (PVDF) (Millipore, Billerica, MA, USA). The expression of different proteins were visualized by chemiluminescence using ECL-Advance Western blotting detection kit (Millipore). The antibody dilutions used for USP39 (ab150393; Abcam) were 1:5,000; $\beta$-catenin (ab19452; Abcam) 1:1,000; TCF4 (ab60727; Abcam) 1:1,000; MMP2 (\#4022; Cell Signaling Technology, Hitchin, UK) 1:2,000; MMP9 (\#3852; Cell Signaling Technology) 1:2,000; GAPDH (ab8227; Abcam) 1:7,500; and goat anti-rabbit IgG H\&R (Abcam) 1:6,000.

Statistical analyses. The data shown are presented as the mean \pm standard deviation (SD) of three independent experiments. All statistical analyses were performed using SPSS 11.0 software (SPSS, Inc., Chicago, IL, USA) and $\mathrm{P}<0.05$ was considered statistically significant. 

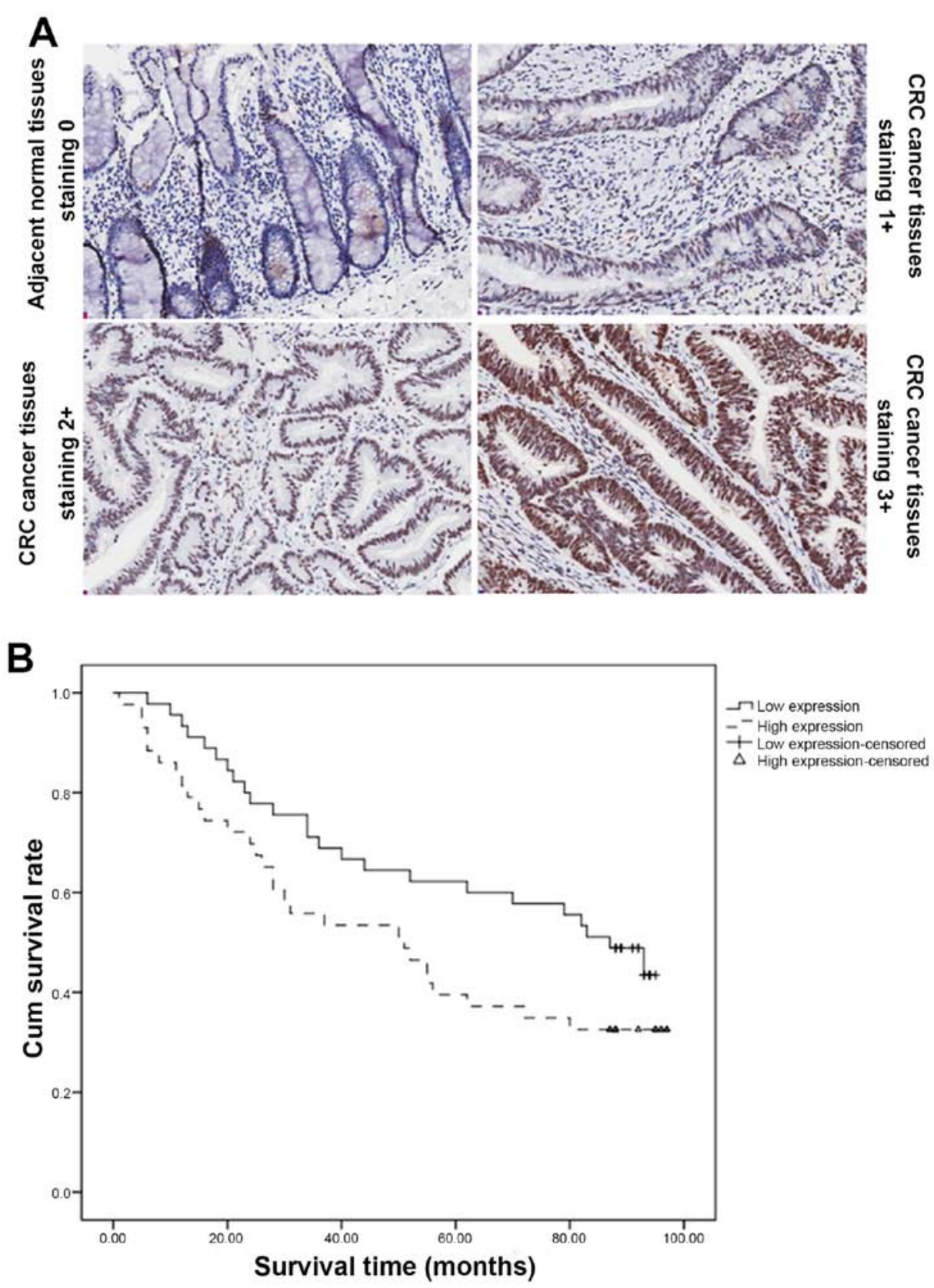

Figure 1. Immunohistochemical analyses of USP39 expression in human tissue microarrays. (A) Representative staining of USP39 expression in tumor tissues and corresponding adjacent normal tissues. Normal colorectal tissues showed weak/undetectable USP39 staining (score 0 or 1+), while tumor tissues showed high (score 3+), moderate (score 2+), or low (score 1+) of USP39 staining. (B) Survival curves of colorectal patients with low vs. high expression of USP39 $(\mathrm{n}=88, \mathrm{P}<0.05, \log$-rank test).

\section{Results}

USP39 expression is upregulated in CRC tumor tissues and correlates with poor patient overall survival. The USP39 expression was examined in human CRC tissue array samples by immunohistochemical staining. The array included 90 CRC patient tissue samples including cancer and corresponding adjacent normal tissues. Among these, 48 tissues samples were from male patients, while 42 were from female patients, with a median age of 71 years (range, 24-90 years). As shown in Table I and Fig. 1A, USP39 had strong expression in CRC tumor tissue samples, as 89 of these showed a score of $\geq 2$. In contrast, adjacent normal tissue samples displayed dramatically reduced USP39 expression, compared with cancer tissues $(\mathrm{P}<0.001)$. In addition, USP39 expression was not associated with other factors. However, KaplanMeier survival curves and the log-rank test survival analysis indicated that CRC patients with high USP39 expression had significantly poor overall survival $(\mathrm{P}<0.05)$, as shown in Fig. 1B. Additionally, the tissue sample analysis of 9 colorectal patients, also revealed significantly higher mRNA and protein levels of USP39 in tumor tissues than corresponding adjacent normal tissues, as shown in Fig. 2.

USP39 knockdown inhibits growth of human CRC cells. Next, we examined the USP39 protein expression in four human CRC 
Table I. The expression of USP39 in human colorectal cancer tissue array.

\begin{tabular}{|c|c|c|c|c|c|c|c|c|c|}
\hline \multirow[b]{2}{*}{ Characteristics } & \multirow[b]{2}{*}{$\mathrm{N}$} & \multicolumn{5}{|c|}{ USP39 expression } & \multirow[b]{2}{*}{ Mean rank } & \multirow[b]{2}{*}{$\mathrm{Z}$} & \multirow[b]{2}{*}{ P-value } \\
\hline & & 0 & 1 & 2 & 3 & None & & & \\
\hline \multicolumn{10}{|l|}{ Gender } \\
\hline Male & 48 & 0 & 10 & 21 & 16 & 1 & 32.47 & \multirow[t]{2}{*}{0.938} & \multirow[t]{2}{*}{0.348} \\
\hline Female & 42 & 1 & 14 & 13 & 14 & 0 & 28.74 & & \\
\hline \multicolumn{10}{|l|}{ Age (years) } \\
\hline$\leq 65$ & 34 & 0 & 9 & 12 & 12 & 1 & 31.45 & \multirow[t]{2}{*}{0.282} & \multirow[t]{2}{*}{0.778} \\
\hline$>65$ & 56 & 1 & 14 & 23 & 18 & 0 & 30.07 & & \\
\hline \multicolumn{10}{|l|}{ Tumor size $(\mathrm{cm})$} \\
\hline$\leq 5$ & 45 & 1 & 12 & 16 & 16 & 0 & 31.13 & \multirow[t]{2}{*}{-0.005} & \multirow[t]{2}{*}{0.996} \\
\hline$>5$ & 45 & 0 & 12 & 18 & 14 & 1 & 30.27 & & \\
\hline \multicolumn{10}{|l|}{ Differentiation } \\
\hline I & 8 & 0 & 2 & 5 & 1 & 0 & 23.50 & \multirow[t]{3}{*}{-0.683} & \multirow[t]{3}{*}{0.247} \\
\hline II & 58 & 1 & 15 & 18 & 23 & 1 & 32.25 & & \\
\hline III & 24 & 0 & 6 & 11 & 7 & 0 & 29.17 & & \\
\hline \multicolumn{10}{|l|}{ TNM stage } \\
\hline I & 2 & 0 & 0 & 2 & 0 & 0 & 26.00 & \multirow[t]{4}{*}{-1.308} & \multirow[t]{4}{*}{0.095} \\
\hline II & 9 & 0 & 5 & 2 & 2 & 0 & 20.22 & & \\
\hline III & 64 & 1 & 16 & 21 & 25 & 1 & 33.00 & & \\
\hline IV & 15 & 0 & 3 & 9 & 3 & 0 & 28.00 & & \\
\hline \multicolumn{10}{|l|}{ Location } \\
\hline Tumor tissue & 90 & 1 & 21 & 34 & 33 & 1 & & \multirow[t]{2}{*}{4.285} & \multirow[t]{2}{*}{0.000} \\
\hline Adjacent tissue & 90 & 3 & 52 & 25 & 9 & 1 & & & \\
\hline
\end{tabular}

A tissue microarray was stained with anti-human USP39 antibody. The staining intensity was scored on a scale of five as follows: negative (0+), weak $(1+)$, moderate $(2+)$ and strong $(3+)$. None means that the site is lost in the section.
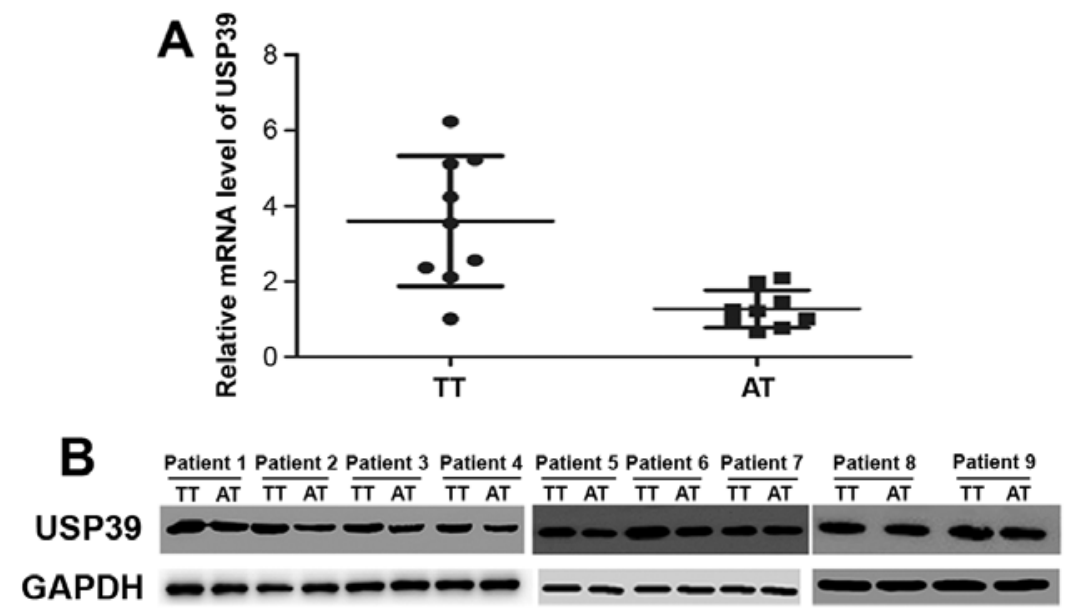

Figure 2. Protein and mRNA level of USP39 in CRC patients. (A) mRNA level of USP39 in tumor tissues and corresponding adjacent normal tissues, using GAPDH as a loading control. (B) Protein level of USP39 in tumor tissues and corresponding adjacent normal tissues, using GAPDH as a loading control. (TT, tumor tissues; AT, adjacent normal tissues).

cell lines, LoVo, Caco2, SW480 and HT-29, using western blot analysis, as shown in Fig. 3A. Our results indicated that indeed all these cell lines have elevated expression of USP39. Next, we knocked down the USP39 expression in these CRC cells and analyzed its effects on their growth, using MTT assay.
As shown in Fig. 3B and C, USP39 knockdown significantly inhibited the growth of HT-29 and SW480 cells, as compared to control knock down (NC). However, the LoVo and Caco2 cells, did not show any significant differences in their growth (data not shown). 

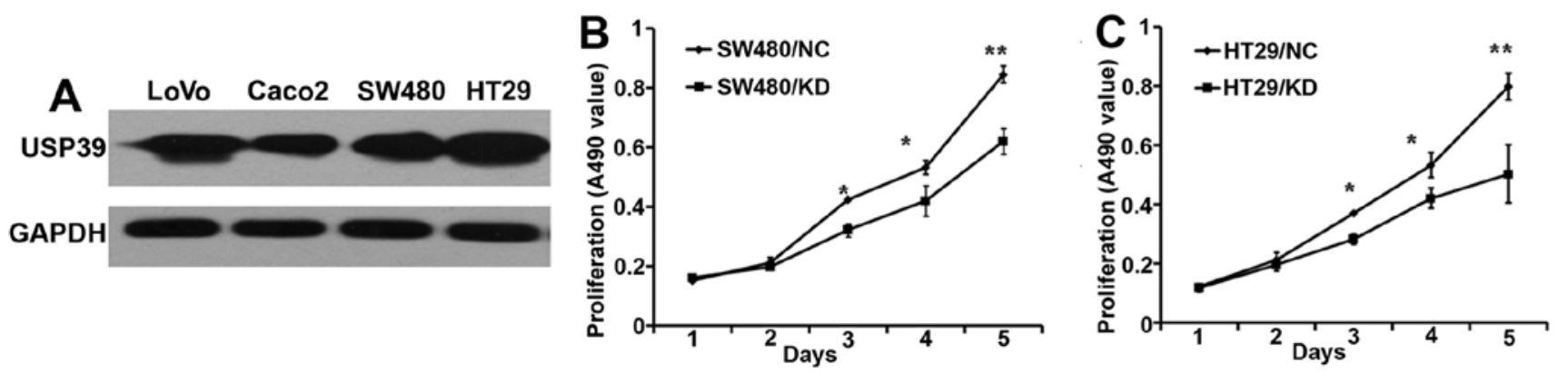

Figure 3. Expression of USP39 and MTT asssay in CRC cell lines. (A) Protein level of USP39 in CRC cell lines. (B) MTT assay to test the cell proliferation in SW480/NC and SW480/KD cells, USP39 knockdown inhibited the growth of SW480. ( $\left.\mathrm{P}<0.05,{ }^{* *} \mathrm{P}<0.01\right)$. (C) MTT assay to test the cell proliferation in HT29/ NC and HT29/KD cells, USP39 knockdown inhibited the growth of HT29. ("P $\left.<0.05,{ }^{* *} \mathrm{P}<0.01\right)$.

A

$\mathrm{Oh}$

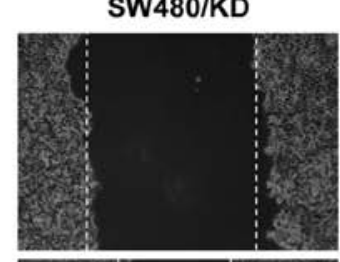

$48 \mathrm{~h}$
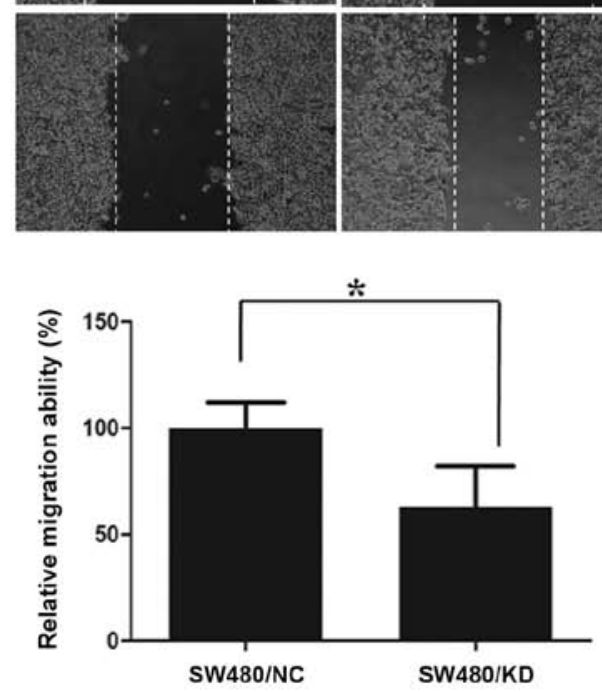

C
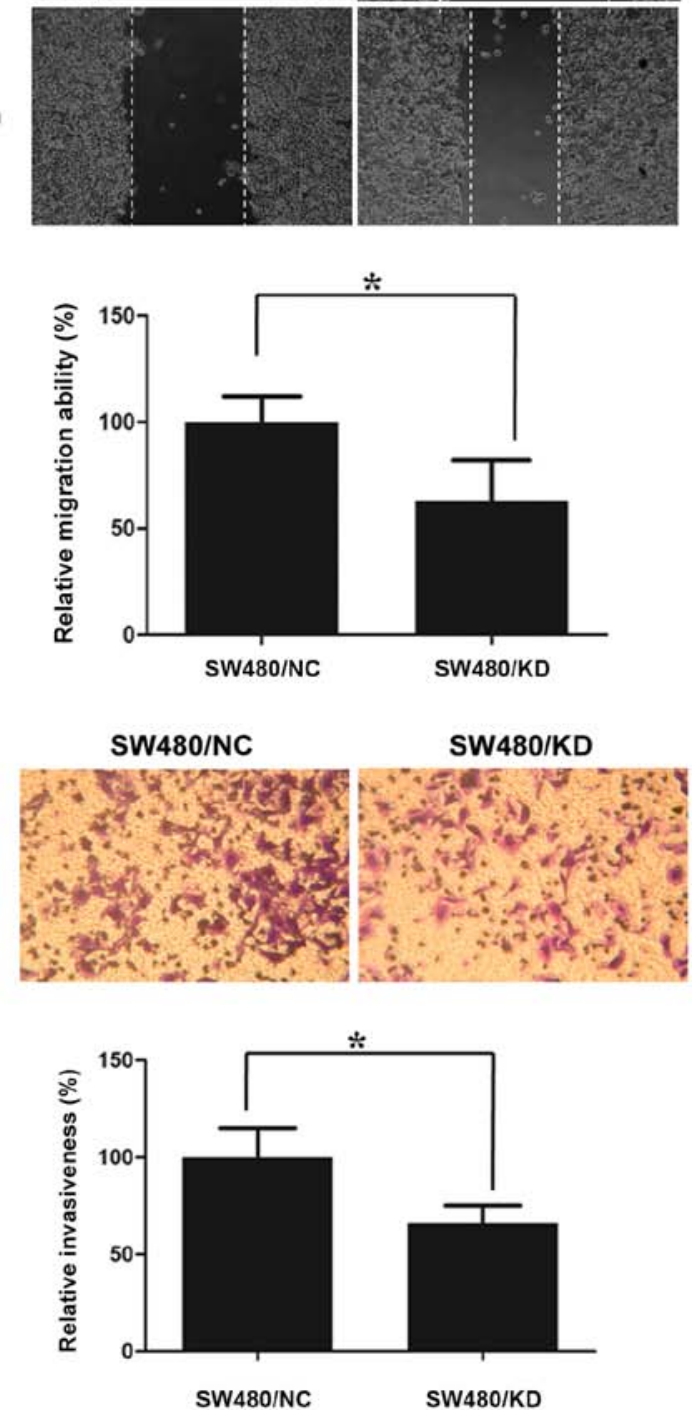

B

$\mathbf{O h}$

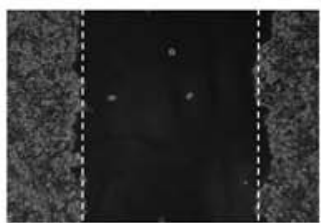

$48 \mathrm{~h}$
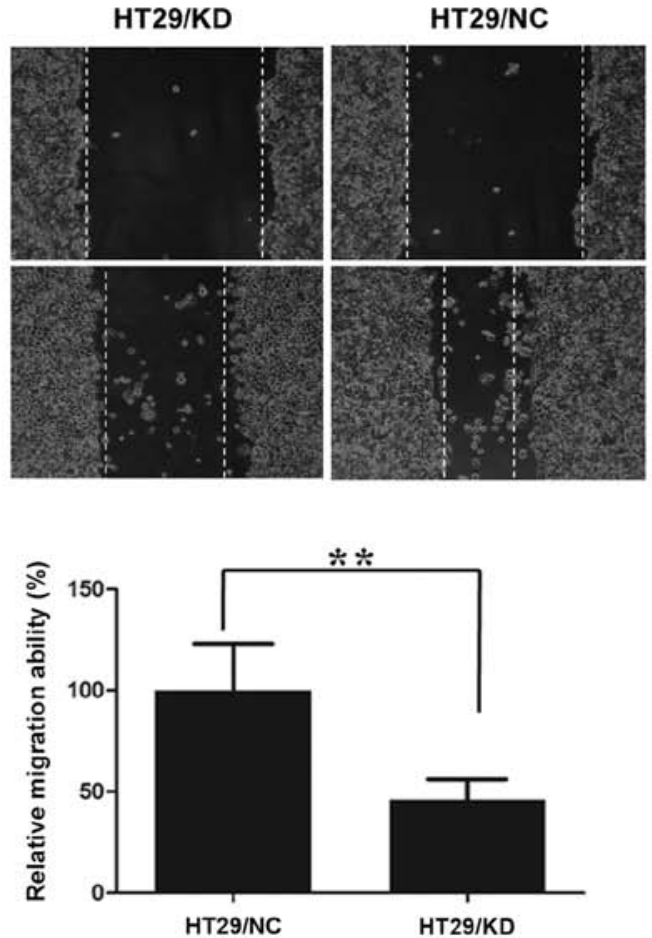

D
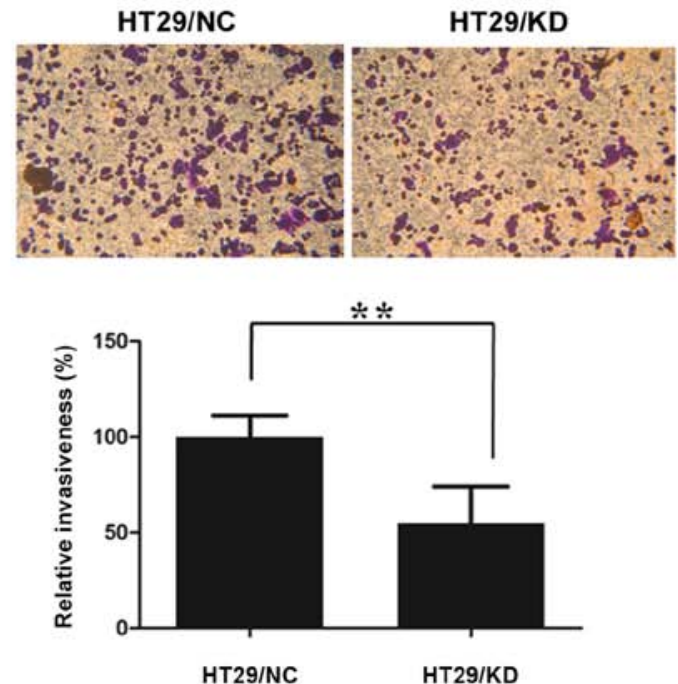

Figure 4. USP39 knockdown inhibits the migration and invasion of CRC cells in vitro. (A) Cell migration was determined by wound healing in SW480 cells transfected by shRNA and negative control. (B) Cell migration was determined by wound healing in HT29 cells transfected by shRNA and negative control. (C) Cell invasion was determined by Transwell assay in SW480 cells transfected by shRNA and negative control. (D) Cell invasion was determined by Transwell assay in HT29 cells transfected by shRNA and negative control. 


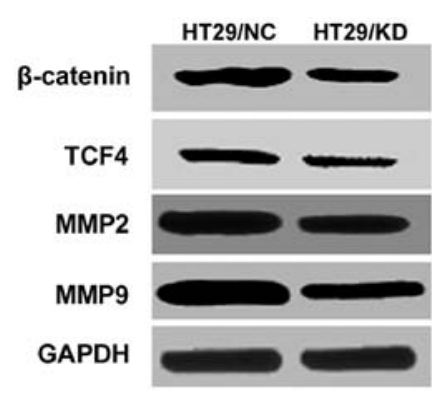

Figure 5. Mechanisms of USP39 regulate the growth of tumor cells. Western blot analysis was carried out to detect the expression of some important molecules including $\beta$-catenin, TCF4, MMP2 and MMP9. These proteins were decreased after USP39 knockdown.

USP39 knockdown inhibits migration and invasion of CRC cells. To assess the USP30 contribution to CRC cell (HT-29 and SW480 cells) migration and invasion, we performed the scratch wound healing assay and Matrigel coated Transwell invasion assay. As shown in Fig. 4A and B, the scratch was about half closed after $48 \mathrm{~h}$ in control knockdown cells, while the USP39 knocked down cells had very little effect on the rate of wound closure. Similarly, USP39 knockdown also reduced the cell invasion of both CRC cell types in comparison to the control knockdown, as shown in Fig. 4C and D.

USP39 knockdown in migration and invasion involved the Wnt signaling pathway. Wnt signaling pathway and its modulators play a significant oncogenic role in CRC development and progression (12-14), we tested the effect of USP39 knockdown on proteins related to $\mathrm{Wnt} / \beta$-catenin pathway and its downstream factor matrix metalloproteinases (MMPs) $(15,16)$. Our results showed that USP39 knockdown significantly reduced the expression of $\beta$-catenin, TCF4, MMP2 and MMP9 proteins, as shown in Fig. 5.

\section{Discussion}

In our previous study, we have shown that USP39 promotes hepatocellular carcinoma (11), however, herein we first demonstrated that USP39 expression in colorectal cancer tissues was higher as compared with corresponding adjacent normal tissues. In addition, we also reported that USP39 was highly expressed in multiple CRC cell lines, and series of in vitro functional experiments revealed that it promotes the growth, migration and invasion of CRC cell lines. Knockdown of USP39 inhibited not only the growth of HT29 and SW480 cells, but also their migration and invasion ability. Further mechanistic insight into its function at molecular level indicated that USP39 might be mediating these effects through regulation of some of the proteins involved in $\mathrm{Wnt} / \beta$-catenin pathway, as $\mathrm{Wnt} / \beta$-catenin pathway has been shown to influence the growth and metastasis of CRC.

Wnt signaling is a crucial mechanism involved in the regulation of cell proliferation, differentiation and morphogenesis (17). Numerous studies have suggested that the abnormal activation of $\mathrm{Wnt} / \beta$-catenin signaling pathway have a significant role in human tumorigenesis, especially colorectal cancer (18). $\beta$-catenin which is the key molecule in this pathway, is a multifunctional protein (19), and acts as a key transcriptional factor in the Wnt pathway. It widely participates in the regulation of cell proliferation and migration $(20,21)$. In the present study, we observed a significant effect of USP39 knockdown on $\beta$-catenin levels, consistent with reduced growth and migration.

MMP2 and MMP9 are proteins expressed on many tumor cells, and act as potential indicators of invasion or metastasis in colorectal tumors (22-24). These MMPs are regulated by $\mathrm{Wnt} / \beta$-catenin signaling pathway $(25,26)$. Activation of cytokine signaling and cell recruitment in the areas of silica dust deposition can lead to excessive disruption of extracellular matrix, which is associated with the secretion of matrix metalloproteinases (MMPs). In the development of pulmonary fibrosis, MMPs specifically cleave important constituents of extracellular matrix (ECM) such as gelatin and collagen, and therefore damage the structure of the alveolar wall (22). It has been reported that $\beta$-catenin mediated expression of matrix metalloproteinases (MMPs) enhance epithelial-mesenchymal transition (27). The key feature of tumor invasion and metastasis is degrading extracellular matrix, and MMPs take part in its degradation, and hence is related closely with the tumor occurrence and development (28). Thus, decreased expression of MMP2 and MMP9 due to USP39 knockdown, coincide with role of USP39 in promoting growth and metastasis in CRC tumor cells.

The treatment of colorectal cancer affecting millions of people worldwide each year, is confronted by the challenges of metastasis, relapse and drug resistance (29). Molecular targeted therapies have become an alternative therapeutic approach, and are being used as a combination therapy with standard chemotherapy agents. For example, the recombinant monoclonal antibody bevacizumab against VEGF-A, and the chimeric monoclonal antibody cetuximab against EGFR have been recently approved for clinical use in combination with 5-FU and irinotecan, respectively, to treat metastatic colorectal cancer $(30,31)$. Thus, identifying novel molecular targets would provide additional options for effective treatment, and the present study suggests that USP39 can be a tentative target for CRC treatment.

In summary, the present study identified that USP39 expression is not only upregulated in CRC patients, but also correlates with their overall survival. In addition, it is involved in regulation of CRC cells growth, migration and invasion. In terms of mechanistic understanding, USP39 effects are mediated through Wnt/ $\beta$-catenin pathway, as its inhibition significantly reduced the expression of many proteins of this pathway. Thus, we conclude that USP39 promotes growth and metastasis of colorectal cancer mainly through the $\mathrm{Wnt} / \beta$ catenin pathway.

\section{Acknowledgements}

The present study was supported by the grants from the National Natural Science Foundation of China (nos. 31300103, 31171306, 31371373 and 31530046); the Clinical Medical Center for Hepatobiliary Disease of Jiangsu Province (no. ZX201105); the Clinical Medical Center for Digestive Disease of Jiangsu Province (no. BL2012001); the Natural Science Foundation of Jiangsu Province (BK20151395); the National Basic Research Program of China (973 program, 
2012CB524900); and the Open Fund of State Key Laboratory of Natural Medicines (no. SKLNMKF201606).

\section{References}

1. Torre LA, Bray F, Siegel RL, Ferlay J, Lortet-Tieulent J and Jemal A: Global cancer statistics, 2012. CA Cancer J Clin 65: 87-108, 2015

2. Goldberg RM, Rothenberg ML, Van Cutsem E, Benson AB III, Blanke CD, Diasio RB, Grothey A, Lenz HJ, Meropol NJ, Ramanathan RK, et al: The continuum of care: A paradigm for the management of metastatic colorectal cancer. Oncologist 12: 38-50, 2007.

3. Zhang J and Manley JL: Misregulation of pre-mRNA alternative splicing in cancer. Cancer Discov 3: 1228-1237, 2013.

4. Ladomery M: Aberrant alternative splicing is another hallmark of cancer. Int J Cell Biol 2013: 463786, 2013.

5. Zhou X, Li X, Cheng Y, Wu W, Xie Z, Xi Q, Han J, Wu G, Fang J and Feng Y: BCLAF1 and its splicing regulator SRSF10 regulate the tumorigenic potential of colon cancer cells. Nat Commun 5: 4581, 2014.

6. Reyes-Turcu FE, Ventii KH and Wilkinson KD: Regulation and cellular roles of ubiquitin-specific deubiquitinating enzymes. Annu Rev Biochem 78: 363-397, 2009.

7. van Leuken RJ, Luna-Vargas MP, Sixma TK, Wolthuis RM and Medema RH: Usp39 is essential for mitotic spindle checkpoint integrity and controls mRNA-levels of aurora B. Cell Cycle 7: 2710-2719, 2008.

8. Ríos Y, Melmed S, Lin S and Liu NA: Zebrafish usp39 mutation leads to rb1 mRNA splicing defect and pituitary lineage expansion. PLoS Genet 7: e1001271, 2011.

9. Wang H, Ji X, Liu X, Yao R, Chi J, Liu S, Wang Y, Cao W and Zhou Q: Lentivirus-mediated inhibition of USP39 suppresses the growth of breast cancer cells in vitro. Oncol Rep 30: 2871-2877, 2013.

10. Huang Y, Pan XW, Li L, Chen L, Liu X, Lu JL, Zhu XM, Huang H, Yang QW, Ye JQ, et al: Overexpression of USP39 predicts poor prognosis and promotes tumorigenesis of prostate cancer via promoting EGFR mRNA maturation and transcription elongation. Oncotarget 7: 22016-22030, 2016.

11. Yuan X, Sun X, Shi X, Jiang C, Yu D, Zhang W, Guan W, Zhou J, Wu Y, Qiu Y, et al: USP39 promotes the growth of human hepatocellular carcinoma in vitro and in vivo. Oncol Rep 34: 823-832, 2015.

12. Lou YF, Zou ZZ, Chen PJ, Huang GB, Li B, Zheng DQ, Yu XR and Luo XY: Combination of gefitinib and DNA methylation inhibitor decitabine exerts synergistic anti-cancer activity in colon cancer cells. PLoS One 9: e97719, 2014.

13. Zhang J, Tsoi H, Li X, Wang H, Gao J, Wang K, Go MY, Ng SC, Chan FK, Sung JJ, et al: Carbonic anhydrase IV inhibits colon cancer development by inhibiting the Wnt signalling pathway through targeting the WTAP-WT1-TBL1 axis. Gut 13: e78-e79, 2015.

14. Park $\mathbf{J}$ and Jeong S: Wnt activated $\beta$-catenin and YAP proteins enhance the expression of non-coding RNA component of RNase MRP in colon cancer cells. Oncotarget 6: 34658-34668, 2015.

15. Jung O, Lee J, Lee YJ, Yun JM, Son YJ, Cho JY, Ryou C and Lee SY: Timosaponin AIII inhibits migration and invasion of A549 human non-small-cell lung cancer cells via attenuations of MMP-2 and MMP-9 by inhibitions of ERK1/2, Src/FAK and $\beta$-catenin signaling pathways. Bioorg Med Chem Lett 26: 3963-3967, 2016.
16. Shalaby MA, Nounou HA, Ms A, O A, Azzam N and Saeed HM: Associations between single nucleotide polymorphisms of COX-2 and MMP-2 genes and colorectal cancer susceptibility in the Saudi population. Asian Pac J Cancer Prev 15: 4989-4994, 2014.

17. Ao N, Liu Y, Bian X, Feng H and Liu Y: Ubiquitin-specific peptidase 22 inhibits colon cancer cell invasion by suppressing the signal transducer and activator of transcription 3/matrix metalloproteinase 9 pathway. Mol Med Rep 12: 2107-2113, 2015.

18. Moon RT, Brown JD and Torres M: WNTs modulate cell fate and behavior during vertebrate development. Trends Genet 13: 157-162, 1997.

19. Xu M, Wang S, Song YU, Yao J, Huang K and Zhu X: Apigenin suppresses colorectal cancer cell proliferation, migration and invasion via inhibition of the $\mathrm{Wnt} / \beta$-catenin signaling pathway. Oncol Lett 11: 3075-3080, 2016.

20. Li X, Zhang X, Liu X, Tan Z, Yang C, Ding X, Hu X, Zhou J, Xiang S, Zhou C, et al: Caudatin induces cell apoptosis in gastric cancer cells through modulation of $\mathrm{Wnt} / \beta$-catenin signaling. Oncol Rep 30: 677-684, 2013.

21. Fu Y, Zheng S, An N, Athanasopoulos T, Popplewell L, Liang A, $\mathrm{Li} \mathrm{K}, \mathrm{Hu} \mathrm{C}$ and Zhu Y: $\beta$-catenin as a potential key target for tumor suppression. Int J Cancer 129: 1541-1551, 2011.

22. Kim W, Kim M and Jho EH: Wnt/ $\beta$-catenin signalling: From plasma membrane to nucleus. Biochem J 450: 9-21, 2013.

23. Tutton MG, George ML, Eccles SA, Burton S, Swift RI and Abulafi AM: Use of plasma MMP-2 and MMP-9 levels as a surrogate for tumour expression in colorectal cancer patients. Int J Cancer 107: 541-550, 2003.

24. Lee MA, Park JH, Rhyu SY, Oh ST, Kang WK and Kim HN: Wnt3a expression is associated with MMP-9 expression in primary tumor and metastatic site in recurrent or stage IV colorectal cancer. BMC Cancer 14: 125-131, 2014.

25. Wu B, Crampton SP and Hughes CC: Wnt signaling induces matrix metalloproteinase expression and regulates $\mathrm{T}$ cell transmigration. Immunity 26: 227-239, 2007.

26. Zuo F, Kaminski N, Eugui E, Allard J, Yakhini Z, Ben-Dor A, Lollini L, Morris D, Kim Y, DeLustro B, et al: Gene expression analysis reveals matrilysin as a key regulator of pulmonary fibrosis in mice and humans. Proc Natl Acad Sci USA 99: 6292-6297, 2002.

27. Orlichenko LS and Radisky DC: Matrix metalloproteinases stimulate epithelial-mesenchymal transition during tumor development. Clin Exp Metastasis 25: 593-600, 2008.

28. Fagan-Solis KD, Schneider SS, Pentecost BT, Bentley BA, Otis CN, Gierthy JF and Arcaro KF: The RhoA pathway mediates MMP-2 and MMP-9-independent invasive behavior in a triple-negative breast cancer cell line. J Cell Biochem 114: 1385-1394, 2013

29. Gill S, Blackstock AW and Goldberg RM: Colorectal cancer. Mayo Clin Proc 82: 114-129, 2007.

30. Cheng YD, Yang H, Chen GQ and Zhang ZC: Molecularly targeted drugs for metastatic colorectal cancer. Drug Des Devel Ther 7: 1315-1322, 2013.

31. Peng X, Luo Z, Kang Q, Deng D, Wang Q, Peng H, Wang S and Wei Z: FOXQ1 mediates the crosstalk between TGF- $\beta$ and Wnt signaling pathways in the progression of colorectal cancer. Cancer Biol Ther 16: 1099-1109, 2015. 